\title{
SOCIEDADE CIVIL, INSTÂNCIAS PARTICIPATIVAS E DESENVOLVIMENTO: O CASO DOS CONSELHOS REGIONAIS DE DESENVOLVIMENTO NO ESTADO DO RIO GRANDE DO SUL
}

\section{CIVIL SOCIETY, PARTICIPATIVE INSTANCES AND \\ DEVELOPMENT: THE CASE OF REGIONAL DEVELOPMENT COUNCILS IN THE STATE OF RIO GRANDE DO SUL}

\author{
Cláudia Tirelli \\ Universidade de Santa Cruz do Sul - Santa Cruz do Sul - RS - Brasil \\ Cíntia Agostini \\ Centro Universitário Univates - Lajeado - RS - Brasil
}

\begin{abstract}
Resumo: $O$ artigo apresenta uma discussão sobre a literatura produzida no Brasil, a partir da década de 1990, em torno dos conceitos de sociedade civil, capital social, participação e desenvolvimento, problematizando os seus aspectos normativos e as suas limitações para a compreensão dos processos verificados empiricamente na sociedade brasileira contemporânea. A partir de uma pesquisa sobre os Conselhos Regionais de Desenvolvimento-COREDES no RS, baseada em análise documental e entrevistas com os seus integrantes, buscou-se investigar como vem se alterando a atuação desses fóruns nas últimas duas décadas e de que forma tem se dado a participação dos distintos atores sociais regionais nesses espaços. $O$ aporte teórico utilizado neste trabalho baseou-se em abordagens recentes produzidas no campo das Ciências Sociais que visam analisar o caráter contingencial das relações entre sociedade civil e democracia e/ou entre instâncias participativas e os processos de desenvolvimento nos diferentes territórios.
\end{abstract}

Palavras-chave: Conselhos Regionais. Sociedade civil. Participação. Desenvolvimento.

Abstract: The article presents a discussion about the literature produced in Brazil, after the 1990s, about the concepts of civil society, social capital, development and participation, questioning its normative aspects and its limitations to the comprehension of the processes empirially verified in contemporary Brazilian society. 
Through a research of the Regional Development Councils (COREDES) in RS, based on the documental analysis and interviews with its members, we sought to investigate how the acting of these forums have changed in the last two decades and how are the distinct regional social actors participating in these spaces. The theorical framework used in this article was based on recently produced approaches in the field of Social Sciences that aim to analyse the contingencial characteristic of the relations between civil society and democracy and/or participative instances and the development proceses in different territorries.

Keywords: Regional Councils. Civil Society. Participation. Development.

\section{INTRODUÇÃO}

Desde os anos de 1990, o debate em torno das relações entre sociedade civil e democracia tem centralizado a atenção de inúmeros pesquisadores nas Ciências Sociais brasileiras. Inicialmente, discutia-se, preponderantemente, a emergência de uma nova sociedade civil e a sua contribuição para a construção de uma sociedade democrática, para além da retomada do Estado de Direito e suas instituições (AVRITZER, 1997; AVRITZER e COSTA, 2004). Aos poucos, o foco dos trabalhos foi se deslocando para a participação da sociedade civil nos novos espaços institucionais que emergiram a partir do início da década de 1990 (conselhos gestores de políticas, fóruns, conselhos de direitos, orçamentos participativos, etc.) e a sua contribuição para a democracia e a eficiência das políticas públicas. As diversas políticas públicas setoriais, conforme já havia sido previsto na Constituição de 1988, passaram a adotar processos participativos desde a fase da elaboração e do planejamento da política, até a sua implementação e avaliação. Também os organismos e agências internacionais começaram a incluir nas suas agendas a defesa e promoção de formas de governança participativa, as quais passaram a ser vistas como sinônimo de transparência, eficácia das políticas públicas e garantia de desenvolvimento (COELHO e FAVARETO, 2012). Conforme salientado por Dagnino, Olvera e Panfichi (2006), a defesa da "participação" das organizações civis, na conjuntura dos anos de 1990, passou a ser um cânone adotado por diferentes atores e projetos políticos, muitas vezes com significados distintos, e até, contraditórios.

A problematização em torno dessas visões normativas, nas quais as instâncias participativas são vistas como produtoras necessárias de 
processos de desenvolvimento dos territórios (nas suas distintas escalas), vem ocorrendo nos últimos anos, mas ainda enfrenta muitos desafios. Um deles está relacionado à necessidade de se produzir mais investigações que propiciem evidenciar, empiricamente, os nexos causais entre participação, democracia e desenvolvimento. Outro se reporta à construção de perspectivas teóricas que permitam sustentar visões menos normativas acerca dos espaços participativos, possibilitando analisar as suas diferenças em termos de desenhos institucionais, relações com a institucionalidade política, recursos diferenciados dos atores no âmbito regional, influência dos fatores culturais, entre outros aspectos. Diante desses desafios, torna-se fundamental a busca por novos instrumentais analíticos que permitam compreender os efeitos da participação sobre os processos de desenvolvimento do território como contingenciais, ou seja, a serem verificados por meio de investigações empíricas e não assumidos como pressupostos.

Este trabalho foi desenvolvido na esteira desses questionamentos, tendo-se em vista que o objetivo consiste em compreender o funcionamento de um desses espaços institucionais de participação, criado na conjuntura dos anos de 1990 no Rio Grande do Sul (RS), os COREDES. A partir de análise documental e de entrevistas realizadas com representantes de 9 dos 28 COREDES 1 (25 entrevistas), pode-se apreender as várias percepções dos participantes dos Conselhos com relação à atuação e representatividade dessas instâncias nas suas respectivas regiões, desde o período de sua fundação até o presente.

Nesse sentido, procurou-se investigar como vêm ocorrendo as articulações de suas lideranças com os atores governamentais nas várias gestões estaduais e de que forma aparecem as dificuldades de participação dos diferentes atores (civis e políticos) na escala regional. Vários trabalhos produzidos sobre essa experiência participativa dos COREDES no RS têm endossado uma visão otimista e, por vezes, idealizada desses fóruns, reiterando as suas qualidades em termos de

1 As entrevistas são parte de um Projeto de Pesquisa intitulado Planejamento e desenvolvimento regional no Rio Grande do Sul: uma análise da experiência recente dos Conselhos Regionais e Desenvolvimento, Financiamento: CNPq EDITAL 18/2012 e FAPERGS/FDRH Edital 16/2012, coordenado pelo professor Dr. Rogério Leandro Lima da Silveira, e desenvolvido no âmbito do Observatório do Desenvolvimento Regional. (SILVEIRA, 2014). 
sua representatividade regional, democracia interna, capilaridade e autonomia frente ao governo estadual. Acredita-se que se possa avançar na compreensão desses processos participativos por meio da adoção de abordagens teóricas menos normativas e, ao mesmo tempo, mais explicativas sobre a conformação histórica do desenho institucional adotado em cada região e sobre como os atores sociais agem nesses espaços.

$\mathrm{O}$ artigo encontra-se estruturado da seguinte forma: na primeira seção, descreve-se o processo de retomada do conceito de sociedade civil no contexto acadêmico latino-americano e brasileiro da década de 1990 e as suas principais críticas; na segunda seção, discute-se a influência da abordagem neotocquevilliana de capital social sobre a produção acadêmica brasileira; na terceira seção, problematiza-se a forma como tem se abordado o nexo causal entre participação e desenvolvimento; por fim, na quarta seção, realiza-se uma análise sobre a experiência dos COREDES no RS, com base em análise documental e entrevistas com os integrantes dos conselhos, à luz das contribuições teóricas trazidas por Lavalle (2003; 2011), Houtzager, Lavalle e Acharya (2004) e Coelho e Favareto (2012).

\section{A RETOMADA DO CONCEITO DE SOCIEDADE CIVIL NO CONTEXTO LATINO-AMERICANO E BRASILEIRO}

No cenário internacional, pode-se afirmar que o conceito de sociedade civil foi retomado nas três últimas décadas do séc. XX a partir, sobretudo, da perspectiva habermasiana. Essa retomada, segundo Foley e Edwards (1998), esteve relacionada à busca por categorias explicativas que pudessem responder aos processos de mudança que vinham ocorrendo no cenário político internacional, tais como a crise do Welfare State e o crescimento de políticas neoliberais na Europa Ocidental, o fim dos regimes comunistas do Leste Europeu e as lutas pela redemocratização em diversos países da América Latina.

No caso da América Latina, esta retomada do conceito se deu, sobretudo, na década de 1990, quando ocorreu um significativo crescimento das organizações civis paralelamente ao processo de redemocratização política e de abertura do Estado à participação da sociedade organizada. No entanto, não se pode afirmar que o conceito 
passou a ser utilizado somente nessa conjuntura dos anos 1990, pois já nas décadas de 1970 e 1980, ele havia alcançado grande repercussão no contexto latino-americano a partir das obras de Antonio Gramsci (DAGNINO, 2000, NOGUEIRA, 2003; NUN, s/d). Conforme Nun (s/d), a abordagem gramsciana permitiu construir uma crítica à parte da intelectualidade latino-americana de esquerda à época, cujos trabalhos se baseavam numa "imagem heroica da política e da classe operária", permitindo perceber as outras vozes (e atores) que se encontravam em situação de subalternidade no mundo da vida cotidiana. No mesmo sentido, Dagnino (2000) salienta que os conceitos gramscianos de "sociedade civil", "hegemonia" e "transformação" contribuíram significativamente para a renovação das análises no campo da esquerda latino-americana naquele período, na medida em que rompiam com o determinismo econômico das análises marxistas mais duras e permitiam repensar as relações entre cultura e política. ${ }^{2}$ Esta perspectiva também possibilitava compreender a contribuição dos movimentos sociais para a reforma intelectual e moral necessária à transformação social, traduzida no vocabulário gramsciano como uma "guerra de posições", na qual a luta política não se restringiria à tomada do Estado, mas se estenderia através da sociedade civil num processo de disputa pela hegemonia entre projetos políticos antagônicos.

Entretanto, essa perspectiva gramsciana de sociedade civil perde espaço com a retração da produção sobre os movimentos sociais no Brasil, ocorrida no final da década de 1980, quando esta é substituída pela produção acadêmica em torno da chamada "nova sociedade civil". A sociedade civil passa a ser o lócus que congrega a pluralidade dos atores civis e que possui a função primordial de construir uma cultura democrática no plano societário. ${ }^{3}$ Nesse sentido, Nogueira (2003) vai afirmar:

\footnotetext{
2 Segundo Dagnino (2000, p. 64), as análises marxistas predominantes naquele período tendiam a ver a "cultura" como o espaço da alienação, pois ela aparecia como dotada de uma dupla negatividade: i) constituir-se como mera expressão de uma essência econômica e ii) ser considerada, portanto, como um obstáculo à transformação social.

3 Alguns balanços apontaram que o refluxo dessa produção acerca dos movimentos sociais esteve relacionado aos seus próprios limites teóricos para explicar a realidade empírica, pois grande parte dos trabalhos apresentava um forte caráter normativo e descritivo. (GOHN, 2007; SCHERER-WARREN e LÜCHMANN, 2004).
} 
Transita-se assim de uma imagem de sociedade civil como palco de lutas políticas e empenhos hegemônicos, para uma imagem que converte a sociedade civil ou em recurso gerencial - um arranjo societal destinado a viabilizar tipos específicos de políticas públicas -, ou em favor de reconstrução ética e dialógica da vida social. (NOGUEIRA, 2003, p. 187).

Apenas no final da década de 1990 e início dos anos 2000, com a emergência de análises críticas na literatura sociológica em relação ao conceito de sociedade civil de Habermas, é que são retomados os conceitos gramscianos de "hegemonia", de "sociedade civil" e de "concepções de mundo", como pode ser visto nos trabalhos de Dagnino 4 (2002), Dagnino, Olvera e Panfichi (2006), Nogueira (2003) e Oliveira (2001).

$\mathrm{Na}$ sociologia brasileira, a incorporação dos conceitos de esfera pública e sociedade civil nos anos 1990 se destacou, sobretudo, nos trabalhos desenvolvidos por Leonardo Avritzer e Sérgio Costa (LAVALLE, 2003). Esses autores buscavam um aporte conceitual que thes permitissem explicar o processo de democratização das sociedades latino-americanas e, em particular, da sociedade brasileira, atentando para a emergência de novos atores na sociedade civil e nas suas capacidades de influir na construção de uma sociedade efetivamente democrática. Avritzer e Costa (2004) apontavam para os limites das interpretações que compreendiam uma sociedade democrática como simples sinônimo da existência de instituições democráticas no plano político (eleições livres e regulares, atividades parlamentares, garantia dos direitos civis), enfatizando a importância de se analisar as mudanças em relação às práticas e atitudes dos atores societários (AVRITZER, 1997; AVRITZER e COSTA, 2004). Na perspectiva de Avritzer (1997), era preciso se debruçar sobre o florescimento de um "novo associativismo civil" constituído a partir de meados dos anos 1970 que, diferentemente do débil associativismo desenvolvido historicamente na América Latina, representaria padrões laicos, pluralistas e autônomos frente ao Estado.

Com esse objetivo, Avritzer e Costa(2004) passaram a utilizar os conceitos de sociedade civil e de esfera pública, produzidos

4 A autora utiliza nos seus trabalhos o conceito de "projeto político" com um significado semelhante ao conceito de "concepção de mundo" em Gramsci. 
originalmente por Habermas e retomados posteriormente por Cohen e Arato (2000), pois interpretavam que essa vertente teórica possibilitaria uma compreensão mais exata dos processos de democratização em curso, na medida em que se debruçava sobre o papel desempenhado pelas organizações civis nesse processo.

Nesse sentido, Avritzer e Costa irão afirmar que foi por meio do conceito de esfera pública que

[...] se identificou, no advento da modernidade, uma esfera para a interação legal de grupos, associações e movimentos [...]. Introduziu-se, assim, a possibilidade de uma relação argumentativa crítica com a organização política, no lugar da participação direta. (AVRITZER e COSTA, 2004, p. 706).

Dentro dessa perspectiva, a esfera pública será percebida como o espaço onde ocorre a produção da opinião pública e da vontade coletiva, espaço no qual se estabelece "[...] a mediação entre o mundo da vida e o sistema político, permitindo que os impulsos provindos do mundo da vida cheguem até as instâncias de tomada de decisão instituídas pela ordem democrática" (HABERMAS, 1990, p. 37 apud AVRITZER e COSTA, 2004, p. 709). Esse modelo discursivo de esfera pública, de acordo com os autores, carrega uma ambivalência, pois esta esfera tanto representa o lócus pelo qual os meios de comunicação buscam engendrar as lealdades políticas e influir sobre as preferências de consumo, como também é o espaço pelo qual se dá a canalização dos fluxos comunicativos do mundo da vida. O conjunto das associações voluntárias, desvinculadas do Estado e do mercado, que possibilitam esse fluxo comunicativo será designado de sociedade civil. Nessa perspectiva, não se poderia mais pensar na sociedade civil através da sua identificação com a sociedade burguesa ou por meio do antagonismo entre sociedade civil e Estado.

Para Avritzer e Costa (2004, p. 704), a incorporação do conceito de sociedade civil nos anos 1990 desempenhou uma função-chave na sociologia da democratização na América Latina, pois permitiu a ressignificação, dentro de um corpo teórico mais amplo, de múltiplos trabalhos pontuais desenvolvidos acerca das relações entre o Estado, as instituições políticas e os novos atores sociais.

No entanto, muitas foram as críticas formuladas a essa visão normativa de sociedade civil. Na sequência, busca-se sistematizar os 
aspectos principais apontados pelos críticos dessa literatura sobre a nova sociedade civil no Brasil.

\subsection{As críticas à utilização do conceito da "nova sociedade civil" no Brasil}

A partir dos anos 2000, vários trabalhos passaram a apontar os limites explicativos da produção sociológica sobre a nova sociedade civil no Brasil (DAGNINO, PANFICHI e OLVERA, 2006; LAVALLE, 2003; 1999; SILVA, 2006; SORJ, 2005, NOGUEIRA, 2003; ABERS e BÜLOW, 2011), salientando os seguintes aspectos: i) a nova sociedade civil foi definida nessa produção em termos essencialistas e normativos, em detrimento das análises empíricas; ii) as distintas esferas societárias (Estado, mercado e sociedade civil) foram concebidas de forma homogênea como se seguissem uma única racionalidade interna; iii) a compreensão das relações entre Estado e sociedade civil ou entre Estado, sociedade civil e mercado seguiu uma perspectiva dicotômica e autonomizante e iv) por fim, negligenciaram-se os estudos empíricos voltados à conformação dos distintos atores da sociedade civil e em relação à sua adesão aos diferentes repertórios de ação.

Com relação ao primeiro aspecto, diversas análises salientaram que o aspecto normativo tendeu a substituir a investigação empírica sobre a sociedade civil, cedendo espaço a uma visão essencialista e prescritiva a respeito da definição dos atores e de como deveriam agir. Sintetizando essa descrição da nova sociedade civil, Lavalle vai dizer que esta

[...] foi definida como uma trama diversificada de atores coletivos, autônomos e espontâneos a mobilizar seus recursos associativos mais ou menos escassos - via de regra dirigidos à comunicação pública - para ventilar e problematizar questões de 'interesse geral'. (LAVALLE, 2003, p. 97).

Segundo esse autor, o problema estava no fato de que as associações e organizações concretas não se enquadravam dentro da prescrição normativa do modelo, o que o levava à seguinte indagação: "[...] afinal, quem integrou a sociedade civil tal como compreendida na 
literatura em questão?" (LAVALLE, 2003, p. 99).5 Ou seja, acabou se instaurando um hiato entre a concepção teórica da sociedade civil e as organizações civis concretas, as quais, muitas vezes, não correspondiam à sua definição na teoria. Essa perspectiva resultava, também, em um direcionamento nas análises, na medida em que os autores tendiam a escolher as organizações que seguissem a definição prescritiva do modelo ou, dito em outras palavras, a eleger aquelas organizações que representassem essa nova sociedade civil, concebida como espontânea, pluralista, laica e democrática. Além disso, esse enquadramento em termos essencialistas e normativos impossibilitava perceber a dinâmica das relações que envolvem a conformação dos atores das sociedades civis reais, naturalizando certos padrões organizacionais e repertórios de ação (LAVALLE, 2003, SILVA, 2010).

Um segundo conjunto de críticas aos estudos sobre a nova sociedade civil refere-se à homogeneização interna conferida às distintas esferas societárias. Isto levou os autores a considerar que os diferentes atores sociais agem nesses espaços de maneira uniforme e buscando os mesmos propósitos. Com relação à dimensão da sociedade civil, vários trabalhos adotaram uma postura crítica em relação a esse postulado (DAGNINO, OLVERA e PANFICHI, 2006; LAVALLE, 2003, 2011), reafirmando a sua heterogeneidade por meio de pesquisas que apontavam para a coexistência de organizações sociais com diferentes ecologias organizacionais, repertórios de atuação e marcos interpretativos, as quais podiam estabelecer formas distintas de relação com as instituições políticas. A esse respeito, Olvera vai afirmar,

[...] a sociedade civil não é um ator coletivo e homogêneo [...] é um conjunto heterogêneo de múltiplos atores sociais, com frequência opostos entre si, que atuam em diferentes espaços públicos e que, via de regra, têm seus próprios canais de articulação com os sistemas político e econômico. Isso quer dizer que a sociedade civil está entrecruzada por múltiplos conflitos e que ela é, em todo caso, uma 'arena de arenas' e não um território de convivência pacífica e não conflituosa.

\footnotetext{
$5 \mathrm{O}$ autor salienta que várias organizações vinculadas à Igreja Católica, aos sindicatos e partidos políticos, tão valorizadas na formação de um campo democrático-popular no Brasil dos anos 1980, passaram a ser mal vistas nesta nova concepção de sociedade civil.
} 
(OLVERA, 2003, p.28 apud DAGNINO, OLVERA e PANFICHI, 2006, p. 23).

Conforme salientaram Dagnino, Olvera e Panfichi (2006, p. 27), algumas organizações que compõem a sociedade civil podem, inclusive, adotar projetos políticos não civis ou pouco democratizantes.

Questionando, igualmente, a uniformidade interna conferida a esses espaços, Sorj afirma que:

nem o mercado, nem o Estado, nem a sociedade civil operam com uma só racionalidade, como mostram, por exemplo, a importância da confiança em relações comerciais, dos valores nos partidos políticos e do poder político e econômico nas organizações da sociedade civil. (SORJ, 2005, p. 13).

Além do mais, como indicam Dagnino, Olvera e Panfichi (2006, p.15), essa uniformização obscurece a possibilidade de identificação e confrontação dos vários "projetos políticos"6 concorrentes no interior dessas esferas. Para esses autores, os discursos e práticas que sustentam esses "projetos" podem ser apropriados por diferentes atores sociais e sofrer alterações e ressignificações nesses processos de apropriação.

O terceiro ponto assinalado pelos críticos relaciona-se à autonomização e dicotomização conferidas na literatura sobre sociedade civil às relações entre Estado, mercado e sociedade civil ou entre Estado e sociedade civil. Sorj formula a sua critica afirmando que

[...] as organizações da sociedade civil podem ser vistas como parte de um continuum mais do que como uma polaridade entre o Estado e o mercado. Elas não só existem graças a condições legais asseguradas pelo Estado, como também devem a maior parte de seus recursos ao Estado e às empresas privadas. (SORJ, 2005, p. 13).

Lavalle (1999, p.130) vai demonstrar que as diferentes linhas argumentativas construídas desde o momento da formulação inicial do

\footnotetext{
6 Segundo Dagnino, Olvera e Panfichi (2006, p. 38), a noção de "projetos políticos" é definida "[...] como conjuntos de crenças, interesses, concepções de mundo, representações do que deve ser a vida em sociedade, que orientam a ação política dos diferentes sujeitos".
} 
conceito de sociedade civil até o momento da emergência do novo modelo de sociedade civil, sempre mantiveram "o caráter absolutamente constitutivo do vínculo entre sociedade e o Estado, equacionado com a introdução da sociedade civil como conceito que cristaliza a mediação entre ambos". Sua crítica em relação ao novo modelo de sociedade civil assenta-se justamente na disjunção que este realiza entre a sociedade e o Estado, ou seja, na oposição externa que estabelece entre eles. Nesta perspectiva, a nova sociedade civil representaria o polo virtuoso dentro de uma relação dicotomizada com o Estado, assumindo um papel de "[...] protagonista de um incessante conflito com o Estado, que, por sua vez, ocupa a posição do antagonista e o polo de valor negativo" (LAVALLE, 1999, p. 131).

Além desses fatores já elencados, ainda se pode acrescentar o fato de que a emergência de muitas organizações da sociedade civil está vinculada à formulação e implementação de políticas públicas por parte do Estado. Por outro lado, as organizações civis também interferem no Estado, seja por meio dos canais institucionalizados de participação, seja por meio da ação direta sobre os atores estatais, os quais, não raramente, provêm dessas organizações e compartilham das suas lutas (ABERS e BÜLLOW, 2011; GOLDSTONE, 2004). Ou seja, a análise das relações e interdependências entre sociedade civil e Estado é crucial para a compreensão das organizações civis e das suas ações.

Por fim, as análises têm detectado a ausência nesse debate de análises empíricas que expliquem o caráter diverso e, por vezes, transitório de constituição dos atores da sociedade civil. Segundo os críticos (SILVA, 2006, 2010; SORJ, 2005; DAGNINO, OLVERA E PANFICHI, 2006; LAVALLE, 2003), isso tem contribuído para a formulação de visões essencializantes e maniqueístas acerca da sociedade civil, pois ela é percebida enquanto uma realidade "dada" e, consequentemente, "natural". Também os elementos que caracterizariam as organizações da sociedade civil aparecem naturalizados, pois estas são descritas, em termos gerais, como organizações virtuosas e voltadas à construção democrática. De acordo com Lavalle (2003) constrói-se, assim, um critério duplo em relação aos atores que compõem a nova sociedade civil: por um lado, há um critério empírico-descritivo relacionado aos atributos que os atores devem conter para integrar esta sociedade civil (espontaneidade, horizontalidade, etc.); por outro, introduzem-se 
exigências normativas, que obrigariam o observador a analisar cada caso e, no limite, estabelecer novos expurgos, na medida em que certas associações passassem a adotar outros repertórios organizacionais e ocupar espaços considerados eminentemente da esfera política.

\section{A PRODUÇÃO DO CAPITAL SOCIAL E O ASSOCIATIVISMO CIVIL}

Assim como a teoria da esfera pública e da sociedade civil de Habermas repercutiu profundamente sobre os cientistas sociais brasileiros nos anos de 1990, um pouco mais tarde passou a ser difundida uma vertente norte-americana que logo foi incorporada por diversos atores da sociedade civil e do Estado: tratava-se da abordagem neotocquevilliana, referenciada principalmente no trabalho de Putnam.

De acordo com Putnam (1996), na sua obra de referência "Comunidade e Democracia: a experiência da Itália moderna", a formação de uma comunidade cívica é fundamental para o bom desempenho das instituições democráticas. Essa comunidade cívica, por sua vez, ampara-se e tem suas normas e valores reforçados a partir das associações civis, as quais produzem efeitos positivos tanto em nível interno, agindo sobre os indivíduos que participam dessas associações, como em nível externo, na sociedade mais ampla. Segundo Putnam (1996, p.103): "No âmbito interno, as associações incutem em seus membros hábitos de cooperação, solidariedade e espírito público." Além disso, o autor (PUTNAM, 1996, p.104) afirma que participar ativamente de associações, mesmo que não sejam de cunho político, aumenta os níveis de "[...] consciência política, confiança social, participação política e "competência cívica subjetiva'”. Em termos externos, a participação em diversas associações produz a "articulação de interesses", incorporando e promovendo a colaboração social. A comunidade cívica pressupõe uma relação de igualdade política, o que implica numa igualdade de direitos e deveres entre os indivíduos. Para o autor (1996, p. 102), esta comunidade cívica "[...] se mantém unida por relações horizontais de reciprocidade e cooperação, e não por relações verticais de autoridade e dependência".

Conforme Foley e Edwards (1998), a definição de capital social para Putnam e seus seguidores envolve qualquer fator das relações sociais que contribui para produzir a habilidade de uma sociedade 
trabalhar conjuntamente e alcançar seus objetivos. Como se viu anteriormente, estas habilidades vão ser produzidas por meio do engajamento dos indivíduos nas associações civis. Foley e Edwards (1998) apontam que as abordagens neotocquevillianas tendem a excluir da sua sociedade civil os grupos e organizações que assumem um caráter conflituoso e a privilegiar aquelas organizações que produzem atitudes e comportamentos de virtude cívica. Esses autores também demarcam que, nessa abordagem, há uma grande ênfase na capacidade da sociedade civil em realizar fins públicos autônomos, sem a direção e o poder estatal. Criticando os neo-tocquevillianos, identificados com o trabalho de Putnam, Foley e Edwards (1998) vão afirmar que ambas as abordagens falham em perceber o quanto o Estado é crucial no enquadramento das iniciativas no interior da sociedade civil, assim como no mercado.

Além disso, diversas críticas têm sido endereçadas à concepção de Putnam em relação ao caráter normativo que ele atribui à sociedade civil, como o locus de realização da autêntica solidariedade e confiança mútua. A crítica formulada pelo institucionalismo histórico questiona o argumento que enfatiza a confiança social como sendo a essência da democracia. Conforme Skocpol e Fiorina (1999), muitas democracias surgiram de relações de desconfiança, as quais deram origem às lutas sociais e, no limite, às revoluções. Além disso, os críticos (FOLEY e EDWARDS, 1998; SKOCPOL e FIORINA, 1999) salientam que a simples participação em associações não pode ser interpretada como promotora de atitudes relevantes para o engajamento cívico e para a democracia. Faz-se necessário indagar a respeito de como os diferentes tipos de associações podem contribuir para o engajamento cívico tal como é considerado pelos neo-tocquevillianos? Que organizações são essas? Quem faz parte delas? Quais são os seus propósitos? Sem essas respostas, apenas seriam endossadas perspectivas apoiadas em visões normativas acerca da sociedade civil e do capital social produzido a partir dos atos de associação. 


\section{AS INSTÂNCIAS PARTICIPATIVAS E OS PROCESSOS DE DESENVOLVIMENTO}

A visão normativa acerca da sociedade civil e capital social também vai estar presente em grande parte dos trabalhos que analisam as instâncias participativas e os seus nexos com os processos de desenvolvimento. Referindo-se a esses trabalhos em torno da governança participativa, Coelho e Favareto (2015) irão afirmar que:

O mecanismo causal proposto para explicar a associação entre governança participativa e desenvolvimento associa [...] a inclusão de um amplo espectro de cidadãos à circulação mais intensa de informação, à maior transparência e legitimidade do processo político e à intensificação do debate público. Esse processo deveria contribuir para ampliar determinadas formas de coordenação, facilitando com isso o desenvolvimento. (COELHO e FAVARETO, 2012, p. 253)

$\mathrm{Na}$ visão dos autores, a literatura sobre este tema tem se dividido entre duas abordagens que partem de pressupostos diferentes para explicar as instâncias participativas e sua contribuição para os processos de desenvolvimento. Segundo Coelho e Favareto (2015), os adeptos das teorias da mobilização defendem que somente haveria inclusão efetiva se os atores mais débeis passassem por processos prévios de empoderamento à sua participação nesses espaços institucionais, caso contrário, seus interesses seriam suplantados por atores mais organizados que concentrariam para si os lucros da participação. Já aqueles autores que se apoiam em abordagens institucionalistas sustentam que a inclusão e a coordenação poderiam ser garantidas a partir de um desenho institucional que reduzisse os custos da participação e atrelasse as contribuições da instância participativa à implementação das políticas públicas. A proposta defendida por Coelho e Favareto (2012) vai no sentido de integrar essas duas perspectivas presentes na literatura sobre governança participativa, buscando compreender como as estratégias dos vários atores e as escolhas referentes ao desenho institucional se combinam nesses processos de diferentes formas, produzindo resultados diversos em termos de coordenação e cooperação voltadas ao desenvolvimento.

As várias críticas que vem sendo formuladas aos trabalhos produzidos em torno do novo associativismo civil, do capital social e 
das instâncias participativas e sua contribuição para o desenvolvimento nos desafiam a superar as visões normativas e ideologizadas sobre esses processos e buscar construir novas possibilidades de investigação sobre as questões que envolvem a participação de distintos atores sociais em processos de governança, novos desenhos institucionais, eficácia de políticas públicas e estratégias de desenvolvimento.

A partir dessas críticas, têm sido formuladas novas perspectivas teóricas que buscam superar os limites apontados para uma melhor compreensão dos processos investigados empiricamente. Nesse sentido, Houtzager, Acharya e Lavalle irão afirmar que

Enquanto a perspectiva da sociedade civil tem prestado pouca atenção aos atores sociologicamente reais e as instituições políticas, a perspectiva da polis preocupa-se primordialmente com análises históricas e comparativas de atores institucionalmente situados. Essa preocupação central ajuda a identificar como atores desenvolvem diferentes capacidades para agir todo tempo. Com efeito, a perspectiva da polis sugere que a participação é um resultado produzido por processos históricos nos quais atores coletivos (organizações civis, atores políticos e outros) negociam relações em um terreno institucional pré-existente que constrange e facilita modalidades particulares de ação (HOUTZAGER, LAVALLE, ACHARYA, 2004, p.40-41, grifo nosso).

Na mesma direção, Coelho e Favareto (2012) justificam essa busca de novas perspectivas de análise a partir do seguinte comentário:

[...] se é verdade que não se pode atribuir um resultado predeterminado a um processo social qualquer, também é verdade que se deve ser capaz de descrever o mecanismo causal que permite explicitar porque, em termos teóricos, é razoável apostar na governança participativa como meio de enfrentar a pobreza e a desigualdade e alcançar o desenvolvimento. (COELHO e FAVARETO, 2015, p. 257).

Essas novas formas de abordar as instâncias participativas é que nortearam esta análise a respeito dos COREDES que será exposta na próxima seção. Buscou-se descrever o processo de formação e atuação dos COREDES, a partir de documentos oficiais, e a percepção dos seus atores sobre o papel desses conselhos para o desenvolvimento das regiões, a sua representatividade e dinâmica de atuação. 


\section{OS CONSELHOS REGIONAIS DE DESENVOLVIMENTO DO ESTADO DO RIO GRANDE DO SUL - COREDES}

Os COREDES surgiram em 1991 como instrumentos de uma política de planejamento regional para o Estado do RS. A partir desse período inicial, quando foram estruturados nas diferentes regiões, os conselhos passaram a funcionar como instâncias de regionalização do estado que buscavam, a partir da discussão e deliberação dos seus membros, constituir as demandas prioritárias para o planejamento e desenvolvimento das regiões. De acordo com Siedenberg,

[...] desde o início da década de 90 até a atualidade, os principais fóruns constituídos e órgãos legalmente instituídos no Estado do Rio Grande do Sul para discutir estratégias e propor políticas e ações voltadas ao desenvolvimento regional, foram os Conselhos Regionais de Desenvolvimento, também conhecidos pela sigla COREDE (SIEDENBERG, 2004, p.135).

De acordo com os documentos analisados (COREDES-RS, 2010; 2014), dentre as justificativas apresentadas para a formação dos COREDES, pode-se destacar as seguintes: i) suprir a falta de órgãos de articulação regional do Estado; ii) constituir um instrumento de mobilização da sociedade capaz de aprofundar a compreensão dos problemas regionais; iii) estabelecer um canal de comunicação entre os órgãos do estado e as regiões; e, por fim, iv) facilitar as parcerias com as administrações públicas (federal, estadual e municipal), possibilitando a participação da comunidade organizada e dos cidadãos na formulação e implementação de iniciativas voltadas para a promoção do desenvolvimento regional.

Desde a criação dos primeiros COREDES até o presente, quando somam 28 Conselhos agrupados em nove regiões funcionais de planejamento, a sua atuação tem se dado junto a diferentes instâncias de planejamento e gestão regional, onde buscam ocupar espaços de influência na definição, no planejamento e na implementação das políticas do Estado do RS em favor das regiões que representam. Segundo constam nos seus documentos, os COREDES são reconhecidos atualmente por outras instâncias e pelo Governo do Estado como um 
fórum que representa os interesses da região. (COREDES-RS, 2010; 2014).

No documento "Pró-RS V- Propostas Estratégicas para o Desenvolvimento Regional do Estado do Rio Grande do Sul - 20152018" encontram-se destacados os segmentos sociais que devem integrar os COREDES. Tendo como perspectiva uma participação ampla da sociedade, estão previstas a participação de atores da sociedade política e da sociedade civil, entre os quais se destacam os seguintes: deputados, prefeitos, presidentes das Câmaras de Vereadores, presidentes dos Conselhos Municipais de Desenvolvimento-COMUDES, representantes de partidos, órgãos governamentais, instituições de ensino, associações, sindicatos, empresários e movimentos sociais. (COREDES-RS, 2014, p.11). Esse documento também preconiza que as atividades desenvolvidas por cada um dos 28 COREDES devem se pautar pelas seguintes diretrizes e ações:

[...] exercer um papel de alta relevância, tanto para as regiões que representam, como para o Estado como um todo e para o Governo Estadual, independentemente de sua composição político-partidária, no desempenho das seguintes atividades: produção e discussão de diagnósticos regionais, visando à elaboração dos Planos Estratégicos de Desenvolvimento Regionais e Estadual e suas respectivas alterações e atualizações, em colaboração com os órgãos estaduais, especialmente, os das áreas do planejamento e das relações institucionais, com as instituições de ensino superior e outras entidades públicas e privadas; - ajudar na identificação das principais necessidades de atendimento no que se refere aos serviços de responsabilidade do Estado; - fiscalizar a qualidade dos serviços prestados pelos órgãos estaduais; - colaborar na busca de fontes alternativas de recursos para o financiamento de investimentos públicos; - apoiar, junto ao Governo Federal, a reivindicações de interesse regional encaminhadas pelo Governo do Estado; - mobilizar a comunidade regional em torno de campanhas de interesse público desencadeadas pelos Governos (COREDES-RS, 2014, p. 10).

Cabe salientar, ainda, conforme expresso no documento PRÓ-RS $V$ (COREDES-RS, 2014), os aspectos referentes aos princípios que devem orientar os COREDES: i) promoção do desenvolvimento regional; ii) autonomia; iii) pluralidade e identificação de consensos; iv) confiança, 
cooperação e formação de parcerias; v) integração, articulação e consolidação das identidades regionais; vi) busca da regionalização das políticas de desenvolvimento; vii) aumento permanente da representatividade dos COREDES nas regiões e nas estruturas e instâncias de Governo; e, por fim, viii) apoio a continuidade das políticas de interesse regional.

Percebe-se, a partir da leitura dos aspectos descritos nesse documento, sobretudo dos seus princípios, o quanto as perspectiva normativas de sociedade civil e de capital social, produzidas ao longo da década de 1990 e início dos anos 2000, também aparecem nos documentos produzidos pelos formuladores de políticas públicas de desenvolvimento regional e pelas próprias lideranças regionais.

Não por coincidência, os COREDES surgiram no contexto pósConstituição de 1988 quando, conforme Avritzer (2009) e ScherenWarren e Lüchmann (2004), abriu-se a possibilidade de criação de diferentes instâncias de participação da sociedade civil. Nesse período, verificou-se a convergência da prática - a criação e gestão de associações, conselhos, entidades - com a discussão teórica do conceito de sociedade civil sob uma perspectiva normativa. Conforme já mencionado no início desse artigo, a defesa da participação da sociedade civil na conjuntura dos anos de 1990 passou a ser feita por diferentes atores e organizações sociais, muitas vezes, vinculada a entendimentos e projetos políticos antagônicos. (DAGNINO, OLVERA e PANFICHI, 2006)

De acordo com Lavalle (1999, p. 134), a rápida influência e incorporação desse modelo idealizado de sociedade civil pelos cientistas sociais brasileiros deveu-se ao fato dele ter fornecido um "eixo de orientação para a ação política" ou, dito de outra forma, uma "via de reflexão para o retorno do ator moral da transformação social". 7

Essa perspectiva normativa também vai estar presente nas entrevistas ${ }^{8}$ realizadas com os integrantes dos COREDES, sobretudo com as suas lideranças. A grande maioria dos entrevistados, na ocasião da

\footnotetext{
7 Lavalle retoma aqui a crítica feita por Gabriel Cohn em relação aos "consensos fáceis" produzidos pela literatura sobre movimentos sociais, a qual estabelecia uma "coincidência entre a esquerda, a ação social e a razão, confrontadas à barbárie do poder." (LAVALLE, 2003, p. 92).

8 Os entrevistados não serão identificados, somente são retirados trechos de suas entrevistas para explicitar a análise aqui proposta.
} 
pesquisa, possuía vínculos muito próximos às estruturas diretivas dos conselhos, na medida em que ocupavam cargos de presidentes, vicepresidentes e secretários dos COREDES, o que certamente conforma um olhar particular acerca desses espaços.

Grande parte dos entrevistados tende a enfatizar a dificuldade dos representantes de diversos segmentos sociais e órgãos públicos em participar ativamente dos COREDES, entretanto, não mencionam os limites conferidos pelo próprio desenho institucional adotado pelos Conselhos que poderiam constranger a participação dos diferentes atores.

Embora os entrevistados afirmem haver uma articulação dos COREDES com os demais atores e organizações civis, por meio da participação de diversas entidades representativas COMUDES, Associação de Municípios, vereadores, setores empresariais, rurais, entre outros), enfatizam que esta participação poderia ser maior e ocorrer de forma mais efetiva. Nesse sentido, alguns entrevistados descrevem que nem todos os segmentos sociais estão articulados suficientemente para atuarem junto aos COREDES. Em um trecho da entrevista de um dos participantes dos Conselhos, este enfatiza que "há um problema na participação, digamos assim, [falta de] engajamento efetivo de liderança dos [...] mais diferentes segmentos". Essa fala se enquadra no problema enfatizado pelas Teorias das mobilizações, descrita na seção 5 , ao referirem a necessidade de empoderamento prévio dos atores mais frágeis, evitando que seus interesses sejam desprezados nas decisões das instâncias participativas em prol dos interesses de atores com maiores recursos.

Ainda em relação à participação, também foi mencionado que um dos graves problemas dos COREDES é a sua representatividade, pois as pessoas são indicadas pelas suas organizações e nem sempre assumem ou, conforme a fala de um vice-presidente, "a instituição não se apropria do poder que tem junto ao COREDE". Um outro entrevistado, que ocupava o cargo de secretário junto ao COREDE, também destaca: "uma das poucas dificuldades é essa participação da comunidade".

Em um fragmento da entrevista de um dos atores, o mesmo indica que diversas entidades são parceiras importantes dos COREDES, mesmo que não participem diretamente. Ou seja, mesmo não participando efetivamente essas estruturas representativas continuam sendo 
lembradas e indicadas como as principais parceiras no processo. Nesse sentido, um dos entrevistados cita a associação dos municípios, a Empresa de Assistência Técnica e Extensão Rural-EMATER, a Empresa Brasileira de Pesquisa Agropecuária-EMBRAPA e as universidades como parceiras importantes dos COREDES ao longo do tempo.

Os problemas referentes aos custos da participação de determinados setores e da captura das demandas do Conselho por setores mais organizados, ou ainda, a forma como determinados segmentos sociais constituem as suas redes diretamente com os atores governamentais, por fora dos COREDES, não foram mencionados nas entrevistas.

Percebe-se que a maioria dos entrevistados apresenta uma visão extremamente normativa dos Conselhos e de sua atuação. Isso fica evidenciado na medida em que nenhum deles enfatizou as dificuldades do próprio Conselho e da sua estrutura de representação. Os fatores negativos apontados são a falta de articulação da sociedade, a baixa participação dos atores, a falta de recursos, a pouca visibilidade que 0 conselho possui na região e, até mesmo, dificuldades político partidárias ou de qualificação técnica.

A representatividade nos Conselhos, conforme os relatos obtidos, se dá de maneira bastante personalista, ou seja, sempre os mesmos indivíduos é que são chamados a participarem dos processos. No entanto, os entrevistados, não externaram nenhum desconforto pelo fato de algumas das diretorias manterem-se nos cargos por muitas gestões, indicando pouca rotatividade nos cargos diretivos dos Conselhos. Pelo contrário, os depoimentos indicam que os integrantes entrevistados acreditam que isso ocorre porque a comunidade assim deseja e que outras pessoas não estariam dispostas a assumir esse papel.

A maioria dos atores entrevistados acredita que os COREDES devem ser o principal ator do planejamento e da gestão das ações em prol do desenvolvimento regional, inclusive, desconsiderando ou não valorizando a ação de outras organizações da sociedade. Poucos percebem que o COREDE tem esse papel de integração das ações em nível regional, mas que ele não é o único representante da região e, portanto, compete com outras instâncias e organizações no processo de 
formação da agenda governamental e na formulação das políticas públicas.

Por fim, os representantes entrevistados indicam que no início da construção dos COREDES, em 1991, havia uma participação mais ampliada da sociedade nas assembleias regionais, microrregionais e locais. No entanto, descrevem que, atualmente, a participação é menor e que há uma dificuldade de engajamento.

Um dos entrevistados explicita essa percepção mais claramente quando afirma,

[..] e lá atrás pessoas muito entusiasmadas que hoje não estão mais junto, e não tão porque se desiludiram com o processo, porque o processo é demorado, porque sei lá. Mas mais de tudo, acho que é uma certa desilusão, e não quer dizer que quem tá errado é o processo, o cara pode ter construído também uma, pode ter idealizado algo que não vai acontecer. Desde o cara que acha que vai fazer a revolução com isso, até o cara que sei lá, que a própria idealização que as pessoas fazem desse tipo de processo, e ele não se concretiza de fato, ou é muito mais demorado do que se imagina no princípio.

Dessa forma, os entrevistados percebem que há um desgaste nas discussões e que a participação deveria ser mais ativa e dar conta das proposições regionais. Contudo, avaliam como positiva a atuação dos COREDES, a sua proposta de representação e articulação social. Em nenhum momento os entrevistados demonstraram qualquer dúvida com relação à necessidade de existência desse fórum, o qual foi criado ao longo do processo de redemocratização e alargamento dos processos participativos no país e no Estado do RS e, dessa forma, poderia não responder mais aos anseios da sociedade nem aos interesses dos atores estatais no presente. Percebe-se, claramente, a permanência de um grupo de integrantes que milita em nome da causa dos COREDES, mesmo apontando para algumas dificuldades surgidas ao longo da sua trajetória.

Bandeira (2010, p.115) retrata, de certa forma, essa posição quando indica que

[...] embora sua atuação ainda enfrente vários tipos de dificuldades, os COREDES conseguiram ocupar uma posição relevante no quadro institucional do Estado, podendo ser considerados uma das mais bem sucedidas experiências desse gênero no país. No entanto, apesar desse relativo sucesso, a 
nova escala territorial representada pelas suas áreas de atuação foi incorporada somente de forma muito superficial à prática da administração pública estadual. Embora tenham ocorrido alguns progressos, os diferentes governos do período não foram capazes de aproveitar adequadamente a potencialidade dessa infraestrutura organizacional, avançando no sentido de criar um modelo abrangente de gestão do território, arejado pela interação entre a administração pública e a sociedade civil.

Tomando-se as entrevistas em seu conjunto, depreende-se uma visão absolutamente positivada e normativa dos COREDES, desde a formulação dos seus princípios, a descrição dos seus objetivos e funcionamento, até a sua articulação com organizações civis e com os atores estatais. Apesar de alguns indicarem haver um decréscimo na participação e dificuldades na representação, poucos identificam estas questões como resultados do próprio processo de construção desses espaços participativos e dos seus desenhos institucionais ou, conforme a linguagem proposta por Lavalle (2011), de construção das diversas sociedades civis realmente existentes. 


\section{CONSIDERAÇÕES FINAIS}

A partir da revisão da literatura realizada neste artigo e da discussão acerca dos seus limites para a compreensão dos espaços de participação empiricamente observados, buscou-se trazer algumas perspectivas de análise que permitam investigar as diversas sociedades civis existentes e como os seus atores se articulam com a institucionalidade política em desenhos institucionais específicos. Com base nos trabalhos desenvolvidos por Lavalle (2003; 2011), Houtzager, Lavalle e Acharya (2004) e Coelho e Favareto (2012), procura-se explicar como as diversas sociedades civis foram conformadas historicamente em nossa sociedade e de que forma esses arranjos institucionais limitam as escolhas dos atores. De acordo com Lavalle,

[...] a construção política da sociedade civil fornece a chave para entender o campo de atuação considerado legítimo para as organizações civis, bem como suas capacidades de escolha, barganha e acordo em face do poder público e de outros atores organizados relevantes. Por conseguinte, não existe um estatuto político da sociedade civil, passível de dedução teórica, mas diversos estatutos, ou, de modo mais incisivo, diversas sociedades civis cujo estatuto não é dado, mas requer explicação (LAVALLE, 2011 , p.8, grifo nosso).

Os COREDES, como outras instâncias participativas, organizações e representações da sociedade civil surgiram nos anos 1990 para cumprir parte do que possibilitava a redemocratização e a Constituição. Inúmeras organizações criadas nesse período não sobreviveram, no entanto, os COREDES se mantêm atuantes em todas as regiões do Estado do RS. A permanência no tempo desses fóruns não significa que se mantiveram inertes, pelo contrário, pode-se perceber mudanças em relação à participação dos atores regionais nesse fóruns, à sua representatividade e à forma de relação com os vários governos estaduais. Cabe salientar, também, a criação de outras instâncias de participação, as quais irão se articular e competir de diferentes formas com os COREDES.

O desafio, hoje, parece se aproximar daquilo que Houtzager, Lavalle e Acharya (2004) enfatizam, ou seja, que se faz necessário saber quem participa, mas muito mais do que isso, deve-se conhecer o que leva os atores a participarem e de que maneira ocorre essa participação. 
Dessa forma, a participação dos diversos atores não é percebida como algo dado, na medida em que as suas estratégias e as escolhas referentes ao desenho institucional se combinam nos espaços participativos de diferentes formas.

Nesse sentido, conhecer a história de cada espaço organizacional e a sua formação social, os recursos disponíveis aos vários atores que o integram, a relação interna entre representantes e representados e as regras e arranjos institucionais dos espaços participativos torna-se essencial para compreender as diversas sociedades civis existentes.

\section{REFERÊNCIAS}

AVRITZER, Leonardo. Um desenho institucional para o novo associativismo. Lua Nova, São Paulo, n. 39, p. 149-174, 1997.

AVRITZER, L. e COSTA, S. Teoria crítica, democracia e esfera pública: concepções e usos na América Latina. Dados - Revista de Ciências Sociais, Rio de Janeiro, v. 47, n. 4, p. 703-728, 2004.

AVRITZER, L. Sociedade civil e participação no Brasil democrático. In: AVRITZER, L. (org.). Experiências nacionais de participação social. São Paulo: Cortez, 2009.

BAQUERO, M. et al. Reflexões sobre a pesquisa nas ciências humanas. Barbarói. Santa Cruz do Sul, n.2, p.17-32, 1995.

COHEN, J. e ARATO, Andrew. Sociedad civil y teoria política. México: Fondo de Cultura Económica, 2000.

COELHO, V. S.P. e FAVARETO, A. Cone4xões entre participação, democracia e desenvolvimento: investigação dos impactos políticos e distributivos da participação social. In: LAVALLE, A. G. (Org.). O horizonte da política: questões emergentes e agendas de pesquisa. São Paulo: UNESP: CEBRAP:CEM, p. 237-260, 2012.

COREDES-RS. PRÓ-RS IV: propostas estratégicas para o desenvolvimento regionais no estado do RS: 2011-2014. Passo Fundo: Passografic, 2010. 
COREDES-RS. PRÓ-RS V: propostas estratégicas para o desenvolvimento regionais no estado do RS (2015-2018). Lajeado: Editora da Univates, 2014.

DAGNINO, Evelina. Cultura, Cidadania e Democracia: a transformação dos discursos e práticas na esquerda latino-americana. In: ALVAREZ, S., DAGNINO, E., ESCOBAR, A Cultura e política nos movimentos sociais latino-americanos: novas leituras. Belo Horizonte: UFMG, p. 61-102, 2000.

DAGNINO, Evelina. Sociedade civil, espaços públicos e a construção democrática no Brasil: limites e possibilidades. In: _-_-- (Org.). Sociedade civil e espaços públicos no Brasil. São Paulo: Paz e Terra, p. 279-301, 2002.

DAGNINO, E; OLVERA, A. J.; PANFICHI, A. Para uma outra leitura da disputa pela construção democrática na América Latina. In: DAGNINO, E; OLVERA, A. J.; PANFICHI, A. (orgs.). A disputa pela construção democrática na América Latina. São Paulo: Paz e Terra; Campinas: Unicamp, p.13-92, 2006.

FOLEY, M. W. e EDWARDS, B. Perspective: Editors' Introduction Beyond Tocqueville: Civil Society and Social Capital in Comparative. American Behavioral Scientist, 42, 5, 1998.

GOHN, Maria da Glória. Teorias dos movimentos sociais: paradigmas clássicos e contemporâneos. São Paulo: Loyola 2007.

HOUTZAGER, P.; LAVALLE, A.G.; ACHARYA, A. Atores da sociedade civil e atores políticos - Participação nas novas políticas democráticas em São Paulo. In: AVRITZER, L. Participação em São Paulo. São Paulo: UNESP, 2004.

LAVALLE, Adrián Gurza. Crítica ao modelo da nova sociedade civil. Lua Nova, São Paulo, n. 47, p. 121-135, 1999. 
LAVALLE, A. G. Sem pena nem glória: o debate sobre a sociedade civil nos anos 1990. Novos Estudos, n 66. Jul.2003.

LAVALLE, A.G. O estatuto político da sociedade civil: evidências da Cidade do México e de São Paulo. Textos para Discussão - CEPAL/IPEA, $\mathrm{n}^{\circ} 28 ; 2011$.

PUTNAM, R. Comunidade e Democracia. Rio de Janeiro: Fundação Getúlio Varas, 1996.

SCHERER-WARREN, I. e LÜCHMANN, L.H.H. Situando o debate sobre movimentos sociais e sociedade civil no Brasil - Introdução. Revista Política e Sociedade, $\mathrm{n}^{\circ} .5$, p.13-35, outubro 2004.

SIEDENBERG, D. R. Condicionantes Político-Administrativos do Desenvolvimento Regional no RS - a experiência dos COREDES. In: WITTMANN, M. L.; RAMOS, M. P. (orgs.). Desenvolvimento Regional: Capital Social, Redes e Planejamento. Santa Cruz do Sul: EDUNISC, v. 1, p. 135-158, 2004.

SILVA, M. K. De volta aos movimentos sociais? Reflexões a partir da literatura brasileira recente. Ciências sociais Unisinos. $46, \mathrm{n}^{\circ} 1$, jan./abr. 2010.

SILVA, M. K. Sociedade civil e construção democrática: do maniqueísmo essencialista à abordagem relacional. Revista Sociologias, Porto Alegre, ano 8, n 16, p.156-179, jul./dez. 2006.

SILVEIRA, R.L.L. da. Planejamento e desenvolvimento regional no Rio Grande do Sul: uma análise da experiência recente dos Conselhos Regionais e Desenvolvimento. Relatório Final de Pesquisa. CNPq/FDRHFAPERGS. Santa Cruz do Sul, dez, 2014.

SKOCPOL, T. e FIORINA, M. Making Sense of the Civic Engagement Debate. In: SKOCPOL, T. e FIORINA. M. (Eds.).Civic Engagement in American Democracy. Washington: Brookings Institution Press; New York: Russell Sage Foundation, 1999. 
SORJ, Bernardo. Sociedades Civis e Relações Norte-Sul: Ongs e Dependência. Rio de Janeiro: Centro Edelstein de Pesquisas Sociais, 2005.

Submetido em 20/07/2015.

Aprovado em 20/10/2015.

\section{Sobre as autoras}

\section{Cláudia Tirelli}

Socióloga, Doutora em Sociologia pela UFRGS. Professora do Programa de PósGraduação em Desenvolvimento Regional e do Departamento de Ciências Humanas da Universidade de Santa Cruz do Sul.

Endereço: Av. Independência, 2293, Bairro Universitário. 96815-910 - Santa Cruz do Sul, RS, Brasil.

E.mail: ctirelli@unisc.br

\section{Cíntia Agostini}

Economista, Mestre em Ambiente e Desenvolvimento, Doutoranda do Programa de Pós-Graduação em Desenvolvimento Regional da Universidade de Santa Cruz do Sul, professora do Centro Universitário UNIVATES.

Endereço: Rua Avelino Tallini, 171, Bairro Universitário. 95900-000 - Lajeado, RS, Brasil.

E.mail: cintia@univates.br. 